\title{
Effect of Implementing a Training Program on the Performance of Primary School Teachers Regarding Disaster Management in Al Malikeyeh - Syria
}

\author{
Basem Essa Abozeed ${ }^{1}$, Zakia Toma Toama ${ }^{2}$, Amina Ahmad Mohamed ${ }^{3}$, Alyaa Farouk Abd El-Fattah Ibrahim ${ }^{4}$ \\ ${ }^{1}$ Lecturer of Community Health Nursing - Syria \\ ${ }^{2}$ Professor of Community Health Nursing, Faculty of Nursing, Alexandria University, Egypt \\ ${ }^{3}$ Assistant Professor of Community Health Nursing, Faculty of Nursing, Alexandria University, Egypt \\ ${ }^{4}$ Assistant Professor of Community Health Nursing, Collage of Nursing-Riyadh, King Saud bin Abdelaziz \\ University for Health Sciences, KSA
}

*Corresponding author - Basem Essa Abozeed

Received 26 February 2019;

Accepted 15 March 2019;

Published 25 March 2019;

\begin{abstract}
Background: Disasters are a global problem, concern every community and no community is immune from it, schools all over the world suffer from disasters, which affect children health and safety. Teachers play essential roles in child protection so, teachers' training is very significant for effective school disaster management. The study aimed to evaluate. The effectiveness of implementing a training program on the performance of primary school teachers in Al Malikeyeh regarding disaster management. Methods: Design: Quasi-experimental design. Setting: the current study conducted in six primary schools at Al-Malikeyeh distracts. Sample: 78 school teachers. Tool of the study: Teacher's knowledge and practice about disaster management structured interview questionnaire which contained three parts: part (I): Socioeconomic data, part (II): knowledge of the teachers, part (III): practice of the teachers .Results: about $35.8 \%$ of teachers had good knowledge pre program; meanwhile post and follow up the program this percent was increased respectively $87.2 \%$ and79.5\%. Also the findings observed that $30.8 \%$ of teachers had satisfactory practice, whereas, respectively $84.6 \%$ and 76.9 of them gained satisfactory disaster management practice post and follow up the program,. Conclusion: Implementing the training program had statistically significant improvement on knowledge and skills of primary school teachers in Al-Malikyeh regarding disaster management. Recommended: Training programs and workshops about disaster issues should be organized for the school teachers and key teams on regular basis, in addition to, awareness campaigns should be implementing with employing mass and social media technologies.
\end{abstract}

Keywords: disasters, Disaster Management, schools teachers, training program.

\section{Introduction}

Disasters are a global problem, causing in widespread human suffering, financial loss and sometimes political instability ${ }^{(1)}$. The disaster events concern every community and no community is immune from it, either natural or man-made ${ }^{(2)}$. The impact on the lives and livelihood of peoples as well as damage to infrastructure are huge. Almost half the world's population has lived through a disaster at some point in the past decade ${ }^{(3)}$. The total number of people affected by disasters in 2016 was 569.4 million. Worldwide, 450 cities with a population over 1 million faced occurring different types of disasters. Managing disasters is one of the most complex development issues, so reducing disaster damages is an essential goal for most governments ${ }^{(4)}$, since all disasters are consequently the result of human failure to introduce appropriate disaster management measures. Understanding a disaster's cause matters as key to disaster risk and vulnerability reduction and to strategize disaster management ${ }^{(5)}$.

Syrian's geo-environmental settings, ecological fragility as well as its conflicts and high degree of socio-economic vulnerability make it one of the most disaster countries in the world. Since 2011, the population is exposed to the largest and most complex humanitarian disasters in the world after the World War II. UN reported in 2017 that, more than 5.6 million Syrians have fled the country and 6.1 million are internally displaced, with more than 13 million people in need for assistance ${ }^{(6)}$. The conflict has caused untold suffering for men, women and children. According to UNICEF report (2017), 8.4 million Syrian children had been affected, more than 4,200 schools have been destroyed and nearly two million children leakage of study ${ }^{(7)}$.

When a disaster strikes, children are among the most vulnerable population group, especially those attending school in times of disaster ${ }^{(8,9)}$. During disasters, school buildings are destroyed, 
taking away the precious lives of children and teachers and stalling access to education in the aftermath of disaster ${ }^{(10)}$. This is supported by the Haiti earthquake in 2 in 2010, the earthquake happened fast and killed about 1300 teachers and 38,000 school children and destroyed more than 4,000 school buildings ${ }^{(11)}$. The effects of disasters on children can be disruptive, injuries which considered as one of the most serious health problems confronting the world today because it can cause lifelong disability or even death, also, the children may experience psychological and behaviors problems ${ }^{(12)}$.

School life is an important part of children's life, which has a direct impact on their mental and physical health. Health promotion and prevention are the most neglected part in both policy and practice. Schools can play a significant role in health promotion due to two major reasons; first, the schools offer structured opportunities for learning and second, pupils spend significant amount of their time in schools during which they are involved in a variety of activities ${ }^{(13)}$. School children and their teachers are some of the most receptive group to disaster preparedness education and training. These children, in turn share this valuable education with family and community. School teachers are valuable social group to educate children about disasters. Therefore teachers must be aware of disaster management in schools and gain knowledge and implement safety practices in school environment. This strategy has proved its long term effectiveness ${ }^{(\mathbf{1 4})}$.

Disaster management programs in schools are important. Performing disaster management actions requires a person's active and accountable participation based on the ability of taking the right decisions ${ }^{(\mathbf{1 0})}$. Health education in disaster management such as providing knowledge and skills, and enhancing people's ability to take correct actions, and the immediate response in an emergency can limit undesirable outcomes or even save lives. Teacher training is important for effective school disaster management. When considering school disaster management, it is clear that school teacher plays an essential role ${ }^{(15)}$. In 2014, Shiwaku pointed out teacher training as a significant issue particularly in the protection of health and safety of school children. Researches on teacher training for school disaster management are not many. However, researches with topics of teacher training for school disaster management contribute to safety in disaster-prone areas ${ }^{(16)}$. The focal points of disaster prevention education should emphasize knowledge of disaster awareness, attitude toward disaster prevention, disaster preparedness, and proper emergency response. School nurses are the link to local public health departments and emergency Services. The school nurse is also in an essential position to provide continuous integration, coordination, and training of all school and community members as a part of the school's emergency management plan ${ }^{(17)}$.

\section{Aims of the study were to}

1. Assess the actual performance of the primary school teachers of Al Malikeyeh regarding disaster management.

2. Develop and implement training program about disaster management for primary school teachers in $\mathrm{Al}$ Malikeyeh.
3. Evaluate the effectiveness of implementing the training program on the performance of primary school teachers in $\mathrm{Al}$ Malikeyeh regarding disaster management.

\section{Hypothesis}

Primary school teachers who attend the training program exhibit competent performance about disaster management than those who don't attend it.

\section{Materials and method}

\section{Study Design \& Setting}

The study is carried out using a quasi experimental research design. It is conducted in the six primary schools in Al Malikeyeh distract which one of four districts affiliated to the Al-Hasaka governorate-Syria.

\section{Subjects:}

By using multistage random sampling technique the following steps were conducted to select the study sample:

- One educational sub-district from the available three subdistricts in Al Malikeyeh district was randomly chosen, according to that Al- Malikeyeh was chosen as the subdistract.

- From of the sub-district (Al- Malikeyeh), six schools were randomly chosen; the first three were selected for the study group and another three for the control group.

- The calculated sample size according to EPI info 7 program was 66 . Then 12 teachers were added in order to overcome issues of mortality and withdrawal from the study.

- Therefore the total subjects'amounted 78 teachers randomly chosen, Thirteen primary school teachers from each of the six schools were selected randomly and included in the study. The teachers were assigned equally to two groups: study group and matched control group.

Tool of the study: One tool was used;

Tool: Teacher's knowledge and practice about disaster management structured interview questionnaire.

Part I- socio demographic characteristics: It included the following data such as name, age, sex, degree of education, years of teaching experience, previously exposed to actual disaster, attended previous program related to disasters.

Part II- knowledge of teachers about disaster management: Comprised of items to assess knowledge of teachers about disaster and its management, it includes questions on the basic concepts of disaster management as; Causes and nature of disasters, effects of disasters, disaster management components role of community/institution in disaster management

Part III- practice of the teachers; in relation to the disaster management: included of items to assess practice of teachers about disaster and its management, it includes questions on the evacuation, search and rescue, basic selected first aids skills, fire safety, security measures and information disseminating.

\section{Scoring system}

The answer for each knowledge and practice item of the teachers was recorded and scored then summed together. 
- For the knowledge of teachers; A scoring system was created from 25 items to evaluating knowledge of primary school teachers about disaster management as follows:

The response for each knowledge item was correctll, wrong\|, missing answer or multi answersll. A score one was given to the correct answer and zeroll was given to wrong answer, missing answer or multi answers. The teachers knowledge is considered good: if the percent score is $\geq 85 \%$, while is considered poor if percent score is less than $85 \%$.

- For the practice of teachers; A scoring system was created from 50 to evaluating practice of primary school teachers about disaster management as follows:

The response for each question was categorized into three levels. These levels were correct complete answer, correct incomplete and incorrect answer. A score twoll was given to the correct complete answer; onell was given to incomplete correct and zeroll was given to incorrect or missing answer. Complete correct $=2$, incomplete correct $=1$, incorrect or missing $=0$. The teachers practice is considered satisfactory: if the percent score is $\geq 85 \%$, while is considered unsatisfactory if percent score is less than $85 \%$.

Validity of the tool (I): The tool was developed by the researchers and checked for its contents which were evaluated by five in the field of community health nursing, acute care nursing and first aids, Faculty of Nursing, Alexandria University; according to their recommendations the modifications and corrections in the tool's contents were done.

Reliability of the tool Reliability was estimated by $\alpha$ Cronbach's test to test internal consistency and its result was equal to 0.81 .

\section{Method}

The steps followed in the present study were:

\section{Administrative process:}

An official permission is obtained by submission of an official letter from the Faculty of Nursing to the responsible authorities of the study setting to obtain the authorization for data collection.

\section{Development and preparation of the study tools:}

Teacher's knowledge and practice about disaster management structured interview questionnaire was developed by the researcher after extensive review of relevant and current literature.

\section{Pilot study:}

It was carried out on 7 primary school teachers before starting the data collection. Those teachers not included in the study sample. The purpose of the pilot study was to ensure the clarity of items and their comprehension, applicability and relevance of the tools, in addition to identify obstacles and problems that may be occurring during data collection. Also, to estimate the time required to fill in the tool. Following to this pilot study, the tool was reconstructed and made ready for use.

\section{Actual field work.}

The training program actually carried out through four following phases: preparatory assessment, developmental, implementation and evaluation.

1. Preparatory assessment phase: Pretest for both study and control groups were conducted by using the tool to assess the knowledge and practice of primary school teachers regarding disaster management.
2. Developmental Phase: The program was developed based on the current literature and the results of the preparatory phase (pretest). The training program steps and methodology was planned to study group, it used a combination of approaches to achieve the program aim as; demonstration and discussion, teaching aids as data show, brain storming, examples, handout, role playing and modeling.

3. Implementation phase: The training program was carried out in a meeting rooms or classes according to availability to encompass a group of 13 teachers. The program was implemented to the study group in the form of six sessions according to their available time with range one session per two weeks for each group; the session took two hours with a break for 10 minute. The collection of data and application of the program lasted over a period of six months, started from January 2015 and ended in June 2015. Different teaching methods as demonstration and discussion, examples, brain storming, teaching aids as data show and visual materials, handout and role playing were used to facilitate the process of educational program to serve the purposes for which it designed.

4. Evaluation phase: Immediately after the end of the training program, the evaluation was performed for both study and control groups to determine the effect of the program on the knowledge and practice of primary school teachers by using teacher's knowledge and practice about disaster management structured interview questionnaire (tool I). The evaluation was repeated after 3 months of program implementation (follow up) to ensure the effectiveness of the disaster management training program which was applied.

Statistical Analysis: The quantitative data were analyzed using Statistical Package for Social Sciences (SPSS) program version 20. Data were presented in tables and figures using actual numbers and percentages. Appropriate statistical methods were applied (percentage, chi-square, ANOVA, correlation coefficient (r), t-test.

Regarding $\mathrm{p}$ value, it was considered that: non-significant if $\mathrm{p}>$ .05 , Significant if $p<.05$.

Ethical Considerations: The aim of the study is explained to teachers before participation, and voluntary participation is emphasized and a written consent is obtained, and the confidentiality and anonymity of the subjects was assured through coding the data. Subjects were also assured that can they withdraw from the study at any time without any rational.

\section{Results}

Table I shows that, among all assessed socio-demographic characteristics, no statistically significant difference was found between the study and control groups. The mean age of teachers in study group was $(32.30 \pm 7.15)$ compare to $(31.87 \pm 6.46)$ of control group. Additionally more than half $(56.4 \%)$ of the study group were females, while the percentage of females in the control group was46.2\%. Regarding income level, the majority of both study and control groups had "not enough" income (respectively, $79.5 \%$ \& $82.1 \%$ ). respectively). The table also depicts that about half $(48.7 \%)$ of the control group had university degree, while, the percentage was $43.6 \%$ in study group. concerning teaching experience, the table revealed that $43.6 \%$ of the study group had 6 to 10 years teaching experience, compared to $38.5 \%$ of the control group. In addition, for witnessing disaster before the time of the 
training program, the table revealed that more than half both study and control groups witnessed disaster previously (respectively, $53.8 \%$ \& 51.3\%). meanwhile, The table also shows that more than

Table 1: Number and percent distribution of school teachers according to their demographic characteristics

\begin{tabular}{|c|c|c|c|c|c|}
\hline \multirow[t]{3}{*}{ Items } & \multicolumn{4}{|c|}{ Groups } & \multirow{3}{*}{$\begin{array}{c}\text { Test of significance } \\
\mathbf{X}^{2} \\
\text { (P value }) \\
\end{array}$} \\
\hline & \multicolumn{2}{|c|}{ Study group $(n=39)$} & \multicolumn{2}{|c|}{ Control group $(n=39)$} & \\
\hline & No. & $\%$ & No. & $\%$ & \\
\hline \multicolumn{6}{|l|}{ Age group ( in years) } \\
\hline $21-25$ & 8 & 20.5 & 8 & 20.5 & \multirow{5}{*}{$\begin{array}{c}X^{2}=2.891 \\
P=0.576\end{array}$} \\
\hline $26-30$ & 11 & 28.2 & 12 & 30.8 & \\
\hline $31-35$ & 13 & 33.3 & 8 & 20.5 & \\
\hline $36-40$ & 3 & 7.7 & 7 & 17.9 & \\
\hline$>40$ & 4 & 10.3 & 4 & 10.3 & \\
\hline Min - Max & \multicolumn{2}{|c|}{$23-53$} & \multicolumn{2}{|c|}{$24-51$} & \\
\hline Mean \pm SD & \multicolumn{2}{|c|}{$32.30 \pm 7.15$} & \multicolumn{2}{|c|}{$31.87 \pm 6.46$} & \\
\hline \multicolumn{6}{|l|}{ Gender } \\
\hline Male & 17 & 43.8 & 21 & 53.8 & \multirow{2}{*}{$\begin{array}{c}X^{2}=0.000 \\
P=0.590\end{array}$} \\
\hline Female & 22 & 56.4 & 18 & 46.2 & \\
\hline \multicolumn{6}{|l|}{ Income } \\
\hline Enough & 2 & 5.1 & 4 & 10.3 & \multirow{4}{*}{$\begin{array}{c}X^{2}=\mathbf{3 . 6 1 1} \\
P=\mathbf{0 . 3 0 7}\end{array}$} \\
\hline Enough and save & 2 & 5.1 & 0 & 0.0 & \\
\hline Not enough & 31 & 79.5 & 32 & 82.1 & \\
\hline Not enough and borrow & 4 & 10.3 & 3 & 7.7 & \\
\hline \multicolumn{6}{|l|}{ Education level } \\
\hline Diploma & 17 & 43.6 & 15 & 38.5 & \multirow{3}{*}{$\begin{array}{c}X^{2}=0.000 \\
P=1.000\end{array}$} \\
\hline University degree & 17 & 43.6 & 19 & 48.7 & \\
\hline High diploma & 5 & 12.8 & 5 & 12.8 & \\
\hline \multicolumn{6}{|c|}{ Teaching experience (in years) } \\
\hline $1-5$ & 13 & 33.3 & 11 & 28.2 & \multirow{4}{*}{$\begin{array}{c}X^{2}=2.172 \\
P=0.704\end{array}$} \\
\hline $6-10$ & 17 & 43.6 & 15 & 38.5 & \\
\hline $11-15$ & 4 & 10.3 & 6 & 15.4 & \\
\hline$>16$ & 5 & 12.8 & 7 & 18.0 & \\
\hline \multicolumn{6}{|c|}{ Disaster witnessed previously } \\
\hline No & 18 & 46.2 & 19 & 48.7 & \multirow{2}{*}{$\begin{array}{c}X^{2}=0.051 \\
P=0.500\end{array}$} \\
\hline Yes & 21 & 53.8 & 20 & 51.3 & \\
\hline \multicolumn{6}{|c|}{ Attended training about disaster issues } \\
\hline No & 22 & 56.4 & 23 & 59.0 & \multirow{2}{*}{$\begin{array}{c}X^{2}=0.053 \\
P=0.500\end{array}$} \\
\hline Yes & 17 & 43.6 & 16 & 41.0 & \\
\hline
\end{tabular}

The data presented in table No.2 shows that, high percentage of teachers in both groups had poor knowledge before the training program about all disaster management' aspects, While, statistical significant differences were found between all disaster management knowledge' aspects scores which include causes and nature of disasters, effects of disasters, disaster risk identification and assessment, disaster risk reduction, preparedness, response- half both study and control groups did not attend any training related to disaster issues (respectively, $56.4 \%$ \& 59.0\%).

Table 2: Distribution of the study and control groups according to their knowledge in relation to the disaster and its management aspects during period of study

\begin{tabular}{|c|c|c|c|c|c|c|c|c|c|c|c|c|c|c|}
\hline \multirow{3}{*}{$\begin{array}{l}\text { Knowledge about disaster } \\
\text { management aspects }\end{array}$} & \multicolumn{7}{|c|}{ Study group $(n=39)$} & \multicolumn{7}{|c|}{ Control group $(n=39)$} \\
\hline & \multicolumn{2}{|c|}{ Pre } & \multicolumn{2}{|c|}{ Post } & \multicolumn{2}{|c|}{ Follow up } & \multirow{2}{*}{$\frac{\mathbf{Z 1}}{\mathbf{P}}$} & \multicolumn{2}{|c|}{ Pre } & \multicolumn{2}{|c|}{ post } & \multicolumn{2}{|c|}{ Follow up } & \multirow{2}{*}{$\frac{\mathrm{Z1}}{\mathrm{p}}$} \\
\hline & No. & $\%$ & No. & $\%$ & No. & $\%$ & & No. & $\%$ & No. & $\%$ & No. & $\%$ & \\
\hline \multicolumn{15}{|c|}{ Causes and nature of disasters } \\
\hline Good & 13 & 33.3 & 25 & 64.1 & 22 & 56.4 & 5.25 & 14 & 35.9 & 15 & 39 & 16 & 41 & 2.26 \\
\hline Poor & 26 & 66.7 & 14 & 35.9 & 17 & 43.6 & $0.031 *$ & 25 & 64.1 & 24 & 62 & 23 & 59 & 0.111 \\
\hline \multicolumn{15}{|l|}{ Effects of disasters } \\
\hline Good & 19 & 48.7 & 28 & 71.8 & 26 & 66.7 & 6.31 & 18 & 46.2 & 16 & 41 & 16 & 41 & 1.68 \\
\hline Poor & 20 & 51.3 & 11 & 28.2 & 13 & 33.3 & $0.021 *$ & 21 & 53.8 & 23 & 59 & 23 & 59 & 0.328 \\
\hline \multicolumn{15}{|c|}{ Disaster risk identification and assessment } \\
\hline Good & 22 & 56.4 & 32 & 82.1 & 30 & 76.9 & 7.01 & 16 & 41 & 20 & 51 & 18 & 46.2 & 2.16 \\
\hline Poor & 17 & 43.6 & 7 & 17.9 & 9 & 23.1 & $0.011^{*}$ & 23 & 59 & 19 & 49 & 21 & 53.8 & 0.107 \\
\hline
\end{tabular}

rescue and relief, and first Aid skills and safety of study group in pre, post and follow up after program, also for control group there was no statistical significant differences between all disaster management knowledge aspects scores except rehabilitation and role of community/institution $(\mathrm{Z}=1.68, \mathrm{P}=0.02)$ during period of the program. 


\begin{tabular}{|c|c|c|c|c|c|c|c|c|c|c|c|c|c|c|}
\hline \multicolumn{15}{|c|}{ Disaster risk reduction } \\
\hline Good & 18 & 46.2 & 28 & 71.8 & 26 & 66.7 & 5.01 & 17 & 43.6 & 22 & 56 & 21 & 53.8 & 2.05 \\
\hline Poor & 21 & 53.8 & 11 & 28.2 & 13 & 33.3 & $0.036^{*}$ & 22 & 56.4 & 17 & 44 & 18 & 46.2 & 0.114 \\
\hline \multicolumn{15}{|c|}{ Preparedness } \\
\hline Good & 20 & 51.3 & 30 & 76.9 & 28 & 71.8 & 5.72 & 19 & 48.7 & 20 & 51 & 18 & 46.2 & 1.75 \\
\hline Poor & 19 & 48.7 & 9 & 23.1 & 11 & 28.2 & $0.031 *$ & 20 & 51.3 & 19 & 49 & 21 & 53.8 & 0.311 \\
\hline \multicolumn{15}{|c|}{ Response-rescue and relief } \\
\hline Good & 18 & 46.2 & 33 & 84.6 & 27 & 69.2 & 7.32 & 15 & 38.5 & 12 & 31 & 14 & 35.9 & 1.27 \\
\hline Poor & 21 & 53.8 & 6 & 15.4 & 12 & 30.8 & $0.01 *$ & 24 & 61.5 & 27 & 69 & 25 & 64.1 & 0.251 \\
\hline \multicolumn{15}{|c|}{ Rehabilitation and role of community/institution } \\
\hline Good & 11 & 28.2 & 18 & 46.2 & 16 & 41 & 5.95 & 10 & 25.6 & 12 & 31 & 11 & 28.2 & 1.68 \\
\hline Poor & 28 & 71.8 & 21 & 53.8 & 23 & 59 & $0.038^{*}$ & 29 & 74.4 & 27 & 69 & 28 & 71.8 & $0.02 *$ \\
\hline \multicolumn{15}{|c|}{ First Aid skills and safety } \\
\hline Good & 12 & 30.8 & 22 & 56.4 & 23 & 59 & 4.22 & 9 & 23.1 & 10 & 26 & 8 & 20.5 & 1.89 \\
\hline Poor & 27 & 69.2 & 17 & 43.6 & 16 & 41 & $0.046^{*}$ & 30 & 76.9 & 29 & 74 & 31 & 79.5 & 0.352 \\
\hline
\end{tabular}

The Fig 1 indicates that, more than one third (35.8\%) of the study group had good total score of knowledge before the training program which was increased to $87.2 \%$ immediately after the program and $79.5 \%$ three months after, with high statistically significant differences $(\mathrm{Z}=17.25, \mathrm{P}=0.001)$, compared to more than half of the control group who had good total knowledge score pre, post and follow up the program (respectively, 40.9\%, 48.7.3 \& $46.2 \%)$ with no significant differences $(\mathrm{Z}=2.03, \mathrm{P}=0.107)$.

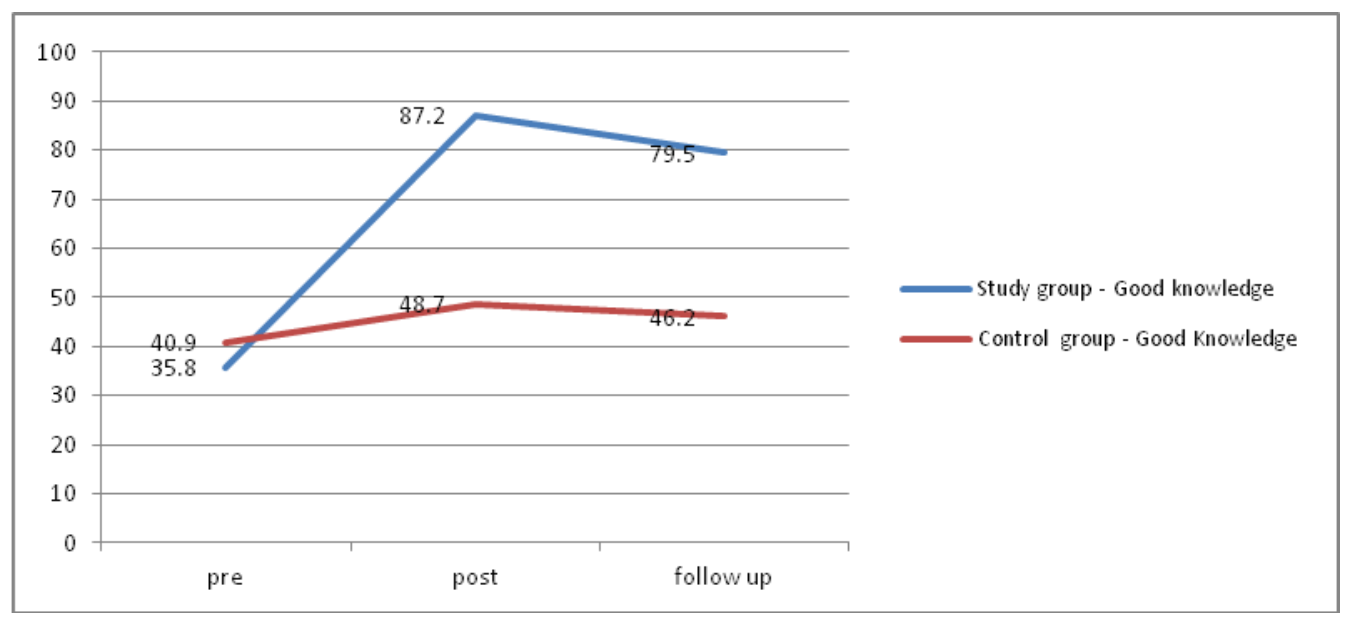

Figure 1: Distribution of study and control groups according to their total knowledge of disaster management pre, post and follow up the training program.

Table No.3 shows that, a statistical significant improvement in the study group was found about all practice' aspects scores which include: evacuation, search and rescue, basic selected first aid skills, fire safety, security measures and information disseminating on the immediate post program and three months after program. As well as no statistical significant improvement in the control group founded about all Practice' aspects during the program period.

Table (3): Distribution of the study and control groups according to their practice in relation to the disaster and its management aspects during the program period

\begin{tabular}{|c|c|c|c|c|c|c|c|c|c|c|c|c|c|c|}
\hline \multirow{3}{*}{$\begin{array}{c}\text { Disaster } \\
\text { Management } \\
\text { Practice aspects }\end{array}$} & \multicolumn{7}{|c|}{ Study group $(n=39)$} & \multicolumn{7}{|c|}{ Control group $(n=39)$} \\
\hline & \multicolumn{2}{|c|}{ Pre } & \multicolumn{2}{|c|}{ Post } & \multicolumn{2}{|c|}{ Follow up } & \multirow[t]{2}{*}{ Z1P } & \multicolumn{2}{|c|}{ Pre } & \multicolumn{2}{|c|}{ Post } & \multicolumn{2}{|c|}{ Follow up } & \multirow[t]{2}{*}{ Z1P } \\
\hline & No & $\%$ & No. & $\%$ & No. & $\%$ & & No. & $\%$ & No & $\%$ & No. & $\%$ & \\
\hline \multicolumn{15}{|l|}{ Evacuation } \\
\hline Satisfactory & 6 & 15.4 & 30 & 76.9 & 26 & 66.7 & \multirow{2}{*}{$\begin{array}{c}6.52 \\
0.015^{*}\end{array}$} & 4 & 10.3 & 2 & 5.1 & 7 & 17.9 & \multirow{2}{*}{$\begin{array}{c}1.98 \\
0.307\end{array}$} \\
\hline Unsatisfactory & 33 & 84.6 & 9 & 23.1 & 13 & 33.3 & & 35 & 89.7 & 37 & 94.9 & 32 & 82.1 & \\
\hline \multicolumn{15}{|c|}{ Search and Rescue } \\
\hline Satisfactory & 9 & 23.1 & 28 & 71.8 & 25 & 64.1 & \multirow{2}{*}{$\begin{array}{c}5.98 \\
0.0225 *\end{array}$} & 6 & 15.4 & 6 & 15.4 & 6 & 15.4 & \multirow{2}{*}{$\begin{array}{c}2.11 \\
0.147\end{array}$} \\
\hline Unsatisfactory & 30 & 76.9 & 11 & 28.2 & 14 & 35.9 & & 33 & 84.6 & 33 & 84.6 & 33 & 84.6 & \\
\hline \multicolumn{15}{|c|}{ Basic selected first aid skills } \\
\hline Satisfactory & 12 & 30.8 & 34 & 87.2 & 30 & 76.9 & \multirow{2}{*}{$\begin{array}{c}6.07 \\
0.014 *\end{array}$} & 8 & 20.5 & 7 & 17.9 & 5 & 12.8 & \multirow{2}{*}{$\begin{array}{c}1.94 \\
0.251\end{array}$} \\
\hline Unsatisfactory & 27 & 69.2 & 5 & 12.8 & 9 & 23.1 & & 31 & 79.5 & 32 & 82.1 & 34 & 87.2 & \\
\hline \multicolumn{15}{|l|}{ Fire safety } \\
\hline Satisfactory & 15 & 38.5 & 30 & 76.9 & 28 & 71.8 & \multirow{2}{*}{$\begin{array}{c}5.71 \\
0.023 *\end{array}$} & 12 & 30.8 & 4 & 10.3 & 4 & 10.3 & \multirow{2}{*}{$\begin{array}{c}1.25 \\
0.336\end{array}$} \\
\hline Unsatisfactory & 24 & 61.5 & 9 & 23.1 & 11 & 28.2 & & 27 & 69.2 & 35 & 89.7 & 35 & 89.7 & \\
\hline \multicolumn{15}{|l|}{ Security Measures } \\
\hline Satisfactory & 18 & 46.2 & 30 & 76.9 & 26 & 66.7 & \multirow{2}{*}{$\begin{array}{c}6.11 \\
0.012 *\end{array}$} & 10 & 25.6 & 6 & 15.4 & 3 & 7.7 & \multirow{2}{*}{$\begin{array}{c}0.98 \\
0.452\end{array}$} \\
\hline Unsatisfactory & 21 & 53.8 & 9 & 23.1 & 13 & 33.3 & & 29 & 74.4 & 33 & 84.6 & 36 & 92.3 & \\
\hline
\end{tabular}




\begin{tabular}{|c|c|c|c|c|c|c|c|c|c|c|c|c|c|c|}
\hline \multicolumn{15}{|c|}{ Information Disseminating } \\
\hline Satisfactory & 8 & 20.5 & 27 & 69.2 & 24 & 61.5 & 5.69 & 7 & 17.9 & 4 & 10.3 & 6 & 15.4 & 0.398 \\
\hline Unsatisfactory & 31 & 79.5 & 12 & 30.8 & 15 & 38.5 & $0.031 *$ & 32 & 82.1 & 35 & 89.7 & 33 & 84.6 & 0.611 \\
\hline
\end{tabular}

* Significant at $\mathrm{P} \leq 0.05 \quad$ Satisfactory $\geq 85$

Fig 2 illustrates that, less than one third $(30.8 \%)$ of the study group had satisfactory total score of practice before the training program which was increased to $84.6 \%$ immediately after the program, and $76.9 \%$ three months after, with high statistically significant differences $(\mathrm{Z}=18.9, \mathrm{P}=0.001)$, compared to the majority of the control group who had unsatisfactory total practice score pre, post and three months after the program (Respectively, $20.5 \%, 12.8 \%$ \& $12.8 \%)$ with no significant differences $(\mathrm{Z}=3.01$, $\mathrm{P}=0.065)$.

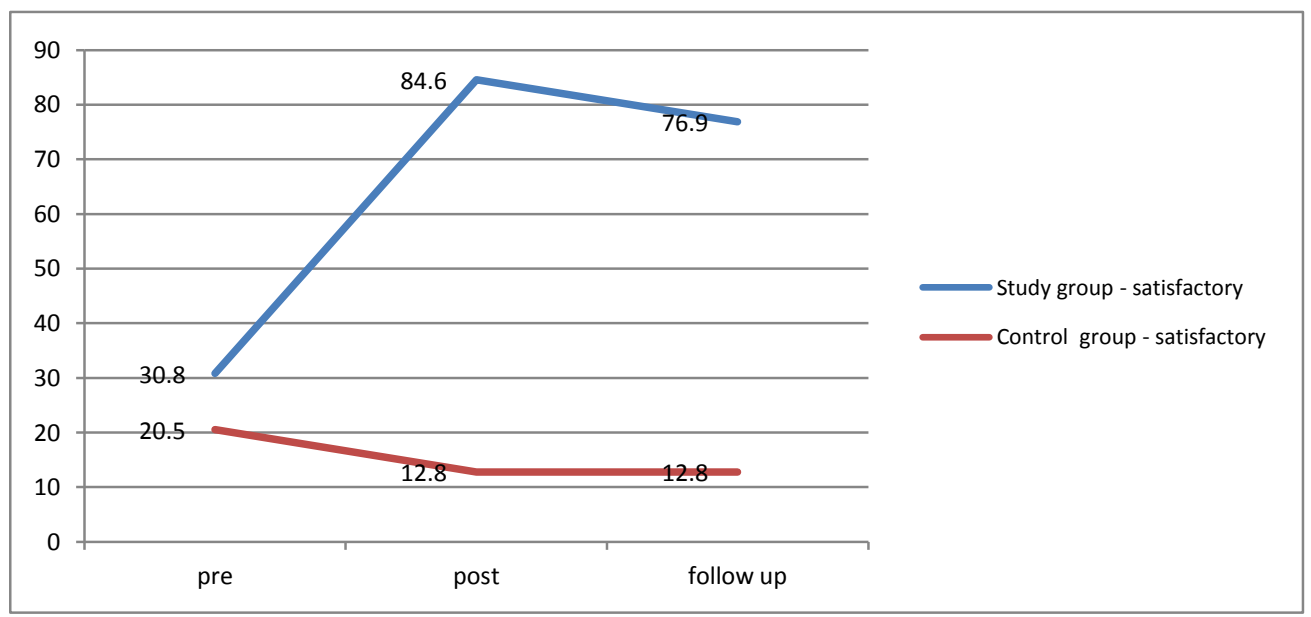

Figure 2: Distribution of study and control groups according to their total practice score in of disaster management pre, immediately post and follow up the training program

Table 4 shows that, there was a positive significant correlation between the score of knowledge and score of practice in the study group at pre, post and follow up of the training program
(Respectively, $\mathrm{r}=.45, \mathrm{p}=0.021 ; \mathrm{r}=0.522, \mathrm{p}=0.001$ \& $\mathrm{r}=0411$, $\mathrm{p}=0.029$ ).

Table 4: Correlation between score of knowledge and score of practice in the study group throughout the training program

\begin{tabular}{|l|c|c|}
\hline \multirow{2}{*}{ Knowledge \& practice } & \multicolumn{2}{|c|}{ Study group } \\
\cline { 2 - 3 } & \multicolumn{2}{|c|}{ P } \\
\hline Pre test & 0.45 & $0.021^{*}$ \\
\hline Post test & 0.522 & $0.001^{*}$ \\
\hline follow up & 0.411 & $0.029^{*}$ \\
\hline
\end{tabular}

* Significant at $P \leq 0.05 \quad r=$ correlation coefficient

\section{Discussion}

School life is an important part of children's life, which has a direct impact on their mental and physical health ${ }^{(13)}$. Children spend most of their time in schools where they are the most vulnerable population to various types of disasters and emergencies, which can influence their present and future health and endanger their life. When considering school disaster management, it is clear that school teachers play an essential role. Teachers are considered as the main caregivers and the firstrespondents in cases of disasters or emergencies during school hours, they must be able to deal properly with disasters and emergencies, so the competence of responders to disasters is one of the cornerstones for successful interventions $(\mathbf{1 0}, \mathbf{1 5})$. The main purpose of the study was to evaluate the effectiveness of implementing the training program on the performance of primary school teachers in Al Malikeyeh regarding disaster management.

Concerning socio-demographic characteristics, results of this study revealed that more than half of teachers of study and control groups witnessed disasters previously. Current finding was in same line with study done by Al-Samghan A et al (2015) who reported that about half of participant teachers had personal experience with children's incidents at school that necessitated fist aid. In relation to attendance of training about disaster issue, more than half of teachers in studied and control groups did not attend training about any type of disaster management aspects ${ }^{(18)}$. This finding come in line with results of Mohamed S (2015) who indicated that about half of the studied sample of schools crisis and disaster committees of the members received training about the evacuation plan and utilization of fire extinguisher ${ }^{(19)}$. On other hand, this result was not supported with study which done by Mamogale H (2011) who reported that the majority of his study subjects $90 \%$ didn't attend any training or workshops on disaster management ${ }^{(20)}$.

In addition, UNESCO 2017 emphasized that teachers must be aware of disaster management in schools, gain knowledge and implement safety practices in school environment. It is noticeable that disaster has significant impact on school children and the facts that confirm safety of them are basic rights of children. Accordingly, there is an urgent need for training program to enhance knowledge and practices of teachers, which help them to manage if an emergency arises ${ }^{(21)}$.

Regarding knowledge of teachers about disaster management, the present study demonstrated that high percentage of teachers in both groups had poor knowledge related to disaster management. While, there was a significant improvement in those teachers who were in study group about knowledge of disaster management on 
the immediate post and three months after program when comparing with the total score of both the study and control group. These findings were in accordance to Mersal et al (2015), who conducted a study in 2016 on impact of a disaster management and first aid guidelines for school teachers in Cairo Egypt, they found that the majority $(1.7 \%)$, of teachers were unsatisfactory knowledge concerning disaster management before the educational program. Meanwhile the percent of them who had satisfactory knowledge significantly increased to $61 \%$ after the educational program implementation, which proved statistically ${ }^{(22)}$. Also, In the same line, Marskole B in 2018, Mhaske in 2012 and Suresh in 2010 found that, the teaching program succeeded in achieving significant improvements among study subjects' knowledge regarding disaster management ${ }^{(23,24,25)}$.

Concerning disaster management knowledge aspects, the present study showed that high percentage of teachers had poor knowledge before the training program. While, majority the teachers had good knowledge about disaster aspects on immediate and three months after program. the present study results were on the same direction with Awad Allah et al (2016) which demonstrated that high percentage of school teachers at Al-Zagazig distract-Egypt had poor knowledge related to general information about disaster before the intervention, and they reported that, there was a highly significant improvement after the intervention, which was proved by the increase in the means of total disaster management knowledge score after the intervention. Also, these findings were supported by the work of Hegazy et al (2014) and Joshi (2015). A probable reason for increasing knowledge score about disaster management and its aspects' may be due to the fact that, the participating in training program has helped the school teachers to reach to the right and necessary knowledge in effective manner, also the training program was motivated the teachers to understand the disaster management aspects, since the disaster management was new concept to most of them.

In regarding practice before the training program, the findings of this study showed that high percentage of school teachers had unsatisfactory practice. While majority the teachers acquired satisfactory practice about disaster with statistical significant difference pre, immediate post and three months after program. These findings were in the same line with a recent study on effectiveness of training manual on disaster management among secondary school teachers at Pune city, Joshi et al. in 2015 reported the effectiveness of training in improving the knowledge and practice of the school teachers. Whereas pre self-express of practice score was 7.05 and posttest self-expressed practice score was 11.93 showing increase by $69.92 \%$, which proved statistically (27). These results were also congruent with findings of Mersal et al (2016) who demonstrated that the majority of school teachers had inadequate practice in terms of disaster management in pre intervention, Mean while, after implementation intervention nearly two thirds of school teachers obtained adequate practice with statistical significant difference in pre and post intervention ${ }^{(22)}$.

Training program plans for the disaster process are including a range of activities at different stages of disaster management. Teachers and students are at the heart of developing a culture of safety. There is much to learn about natural hazards, disaster prevention, environmental protection, personal safety, emergency preparedness, response procedures and skills ${ }^{(11)}$.

Concerning of disaster management practice aspects of school teachers' which include: evacuation, search \& rescue, basic selected first aid skills, fire safety, security measures and information disseminating in study group. The present study revealed that a most of subjects had unsatisfactory practice about all disaster management aspects before the program. Whereas after the program, most the subjects had satisfactory practice about all practice' aspects scores. This result was congruent with finding of Riad et al. (2013) who reported that, there was a significant improvement in score of skills after the program implementation in terms of first aid, response to crisis management and evacuation of students during fire, which proved statistically ${ }^{(28)}$. Moreover, the finding of this study was in the same line with Adiyoso .W (2013) note, which indicated that, during practice, evacuation and response procedures should be practiced, evaluated and improved (29)

These findings could be attributed to improve knowledge among teachers increase their understanding and practices regarding disaster management and its aspects. On other explanation of this findings that, training program not only focuses of theory concepts, but also on practical issues, these encourage the teachers to right practices. Furthermore, Syria is at war so the teachers had highly motivated to get right knowledge practices since they thought that, they will need these procedures later to help their families and communities in crises cases.

The finding of current study revealed that there were statistically significant positive correlation between knowledge and practice for the study group throughout the study period. This result was in the same line with Awad Allah et al (2016) and Muneeswari (2014) who confirmed that there was significant correlation between knowledge and practice of disaster management and first aid during the study stages $(26,30)$.

\section{Conclusion}

The results illustrated a general lack of knowledge and unsatisfactory performance among school teachers regarding disaster management. However, the training program was effective in enhancing knowledge and practice of disaster management, which proved statistically. In addition, the study found positive correlation among demographic variables of school teachers' knowledge, practice of disaster management. In addition, it was found positive correlation among knowledge and practice of disaster management.

\section{Recommendations}

1. Establish a comprehensive plan for disaster preparedness, strengthening capacities for disaster risk reduction and developing skills for making communities are ready to deal with crises at any time.

2. Each school must prepare its own School Disaster Management Plan and must be updated on regular basis.

3. Training programs and workshops about disaster issues should be organized for the school teachers and key teams on regular basis.

4. Similar study can be conducted among school students, college students, and general public.

\section{References}

[1] Pelling M. 2012.The vulnerability of cities: natural disasters and social resilience. UK: Routledge. 
[2] Gowdy J. 2013. Coevolutionary economics: the economy, society and the environment. Germany: Springer Science \& Business Media;

[3] Caldera HJ. 2017. Analysis and classification of natural disasters. Canada: University of Calgary.

[4] Centre for Research on the Epidemiology of Disasters (CRED), 2017.Institute of Health and Society (IRSS). Annual Disaster Statistical Review The numbers and trends 2016. Belgium: CRED, IRSS;

[5] Okoli AC. 2014. Disaster management and national security in Nigeria: The nexus and the disconnect. International Journal of Liberal Arts and Social Science; 2(1):21-59.

[6] The United Nations Office for the Coordination of Humanitarian Affairs (UNOCHA). 2017. Humanitarian Needs Overview. USA, Switzerland: UNOCHA.

[7] The United Nations International Children's Emergency Fund (UNICEF). 2017. Syria Crisis Situation Report (Humanitarian Results). USA: UNICEF;

[8] Blaikie P, Cannon T, Davis I, Wisner B. 2014. .At risk: natural hazards, people's vulnerability and disasters. UK: Routledge.

[9] Peek L, Stough LM. 2010. Children with disabilities in the context of disaster: A social vulnerability perspective. Child Development; 81 (4):1260-1270.

[10] National Association of School Psychologists (NASP). 2013. A framework for safe and successful schools. USA: NASP.

[11] Benjamin E, Bassily-Marcus AM, Babu E, Silver L, Martin ML. 2011. Principles and practice of disaster relief: lessons from Haiti. Mount Sinai Journal of Medicine: A Journal of Translational and Personalized Medicine; 78(3):306-318.

[12] International Federation of Red Cross and Red Crescent Societies (IFRC). 2018. Case Studies: Red Cross Red Crescent Disaster Risk Reduction in Action - What Works at Local Level. Geneva, IFRC.

[13] Strang S. 2012. A Comprehensive School Safety Plan for a Rural High School: Enhancing Safety \& Security. PhD Thesis. Faculty of the School of Education: Northcentral University.

[14] Hegazy M, Shounoda M, Ismail G. 2014. Impact of a Disaster Educational Program on Knowledge and Practices of Teachers among Primary Governmental Schools, Cairo Governorate. Journal of Education andPractice; 5(29): 175184.

[15] The United Nations Office for Disaster Risk Reduction (UNISDR). 2008. Disaster Prevention for Schools Guidance for Education Sector Decision-Makers: Consultation version. Thematic Platform for Knowledge and Education. USA: UNISDR.

[16] Shiwaku K, Shaw R. Proactive co-learning: a new paradigm in disaster education. Disaster Prevention and Management: An International Journal 2014; 17(2):18398.

[17 Stanley S, Cole S, McGill J, Millet C, Morse D. The Role of the Public Health Nurse In Disaster Preparedness, Response, and Recovery. 2nd ed. USA: Association of Public Health Nurses; 2013.

[18] Al-Samghan AS, Al-Shahrani FM, Al-shahrani FH. 2015. Primary School Teachers' Knowledge about First-Aid, medical journal cairo university; 83(1): 541-607.

[19] Mohamed S. 2015. Disaster management measures adopted by schools in Alexandria. Master thesis. Nursing Fuculty. Alexandria University.

[20] Mamogale H. 2011.Assessing disaster preparedness of learners and educators in Soshanguve North schools. Master Thesis. Disaster Management Training and Education Center for Africa, University of the free state.
[21] The United Nations Educational, Scientific and Cultural Organization (UNESCO). 2010. School safety manual: tools for teachers. France: UNESCO.

[22] Mersal FA, Aly RA. 2016. Developing disaster management and first aid guidelines for school teachers in Cairo Egypt. Journal of Nursing Education and Practice; 6 (7): 41-53.

[23] Marskole P. 2018. A study to assess awareness on disaster management among school going children in Gwalior (M.P.). International Journal of Community Medicine and Public Health; 5(4):1371-1375.

[24] Mhaske S. 2012. Knowledge regarding disaster management among secondary school teachers. Sinhgad eJournal of Nursing; 2(2): 27-39.

[25] Suresh S. 2010. Effectiveness of structured teaching program on knowledge and practices of disaster management among school teachers. Nightingale Nursing Times: 6(6):44-57

[26] Awad Allah MB, Salem GM, Said RM. 2016. Enhancement of Disaster Management and First Aid Rules for Primary School Teachers in Egypt. Journal of High Institute of Public Health; 46(2):61-78.

[27] Joshi SG, Sawane K, Jabade M. 2015. Effectiveness of training manual on disaster management in terms of knowledge and self-expressed prac- tices among secondary school teachers in selected schools of Pune city. International Journal of Science and Research (IJSR); 4(9): 2093-2106.

[28] Riad NA, Rabea FM, Badawy AI. 2013. Capacity Building of Females Governmental Secondary School Teachers in Abha City For Crises Management \& First Aid. Journal of Education and Practice; 4(23): 33-41.

[29] Adiyoso W, Kanegae H. 2013. Effectiveness of disasterbased school program on students' earthquakepreparedness. Journal of Disaster Research; 8(4): 10091017.

[30] Muneeswari B. 2014. A study to Assess the Effectiveness of Planned Health Teaching Programme Using Child-to Child Approach on Knowledge of Selected First Aid Measures among School Children in Selected Schools at Dharapuram in Tamil Nadu, India. Global Journal of Medicine and Public Health; 3(1): 18. 